\title{
A mídia de colunismo social porto-alegrense: uma análise do programa Sociedade
}

\author{
Pink press media in the city of Porto Alegre: \\ an analysis of Sociedade program
}

\begin{abstract}
Ani Mari Hartz Born
Doutoranda em Ciências da Comunicação pela Universidade do Vale do Rio dos Sinos (UNISINOS), professora Adjunta do Programa de Graduação em Publicidade e Propaganda, Design e Administração de Empresas na Escola Superior de Propaganda e Marketing (ESPM/RS), Porto Alegre, RS - Brasil, e-mail: aborn@espm.br
\end{abstract}

\section{Resumo}

Este artigo propõe analisar o programa Sociedade, com Odalgir Lazzari, veiculado tanto na televisão por assinatura quanto na web. Nesse sentido, adotam-se como objetivos específicos identificar as características dos tipos de mídias empregados pelo programa nos diversos suportes midiáticos em que é veiculado, verificar os tipos de elites e revelar suas categorias temáticas. Para tanto, o corpus de pesquisa selecionado foi quatro edições do programa Sociedade no ano de 2009, tendo a técnica de análise de conteúdo como forma de apreciação dos dados. Dentre os principais resultados destacam-se as nove categorias temáticas encontradas: mar de afetividade, império da adjetivação, o popular e o elitizado, pluralidade de elites, era da aparência, reino de Deus, bordões, ajudando a pagar a conta e retroalimentação.

Palavras-chave: Mídia. Colunismo social. Programa Sociedade.

\section{Abstract}

This article aims to analyze Sociedade program, with Odalgir Lazzari, aired on pay TV and in the web. In this sense, it tries to identify the characteristics of media types used by the program in its several media supports, check the types of elites and reveal the thematic categories. To this end, four editions of Sociedade program in 2009 were selected as the body of research, using the technique of content analysis as a means of data analysis. Amongst the main results were these nine categories found: sea of affection, empire of adjectivation, the popular and the elitist, plurality of elites, appearance era, God's kingdom, rods, belping to pay the bill and feedback.

Keywords: Media. Pink press. Society Program. 


\section{Introdução}

A mídia de colunismo social diz respeito a um gênero do jornalismo que contempla assuntos como celebrações privadas (casamentos, aniversários, nascimentos), celebrações coletivas (shows, bailes), pessoas da sociedadelocal, pessoas famosas (reconhecimento nacional/mundial), locais das celebrações (nomes dos clubes, igrejas, associações), propaganda (anúncios pagos), publicidade (reportagens, notas por meio de releases, lançamentos de empresas/ produtos), cultura (exposições, livros), beneficência (caridade, doações, cunho social), profissionais do mercado, saúde/beleza e moda (BORN, 2008a).

A partir da noção de colunismo social de Aronchi de Souza (2004) para a televisão, estende-se para outros meios de comunicação (jornal, revista e web) e também para além da definição proposta pelo autor (um misto de talk show, propaganda institucional e telecompras) (BORN, 2008a).

$\mathrm{Na}$ cidade de Porto Alegre, RS, a mídia de colunismo social é retratada nas revistas South Star, Versatille, Moinhos, Estilo Zaffari e Tomorrow Magazine; nos jornais, com as colunas como a RSVIP, de Mariana Bertolucci, do jornal Zero Hora, Gasparotto, de O Sul, Eduardo Connil, do Correio do Povo, e Eduardo Bins Ely, do Jornal do Comércio; e ainda no meio televisivo, com os programas Zoom, da Rede Pampa, com Fernando Vieira, e Sociedade, do canal 20, com Odalgir Lazzari, também veiculado na web pelo portal TVI. Há também, veiculado apenas na web, a coluna social do Décio Azevedo, no portal Qualé a boa. Sobre a veiculação na televisão e na web, Luca (2009), baseada na pesquisa do Ibope Nielsen
Online, destaca que aproximadamente 10 milhões de brasileiros assistem à televisão em casa via internet.

Nesse contexto, o presente artigo tem como principal objetivo analisar o programa Sociedade com Odalgir Lazzari, por ser veiculado tanto na televisão quanto na webe também pelo tempo de existência no mercado porto-alegrense (nove anos na televisão e um ano na internet). Objetiva também identificar as características dos tipos de mídias empregados pelo programa Sociedade nos diversos suportes midiáticos em que é veiculado, verificar os tipos de elites ${ }^{1}$ que busca construir e revelar as categorias temáticas do programa.

\section{Referencial teórico}

\section{Televisão e web}

Em virtude da internet, houve modificação nos hábitos televisivos (VILCHES, 2003). Luca (2009, p. 1), com base em José Calazans, analista de internet do Ibope, afirma que o número de internautas " [...] registrado em março cresceu $17 \%$ em relação a fevereiro deste ano [2009]. Na comparação anual com março de 2008, quando a audiência era de 8,6 milhões de usuários, houve um aumento de $12 \%$ na audiência de TV online", se referindo às pessoas que assistem à televisão em casa via web por meio de portais - como, por exemplo, assistir novelas e séries da TV Globo no portal Globo.com (http://www.globo.com/).

Mielniczuk (2003), a partir de Pavlik, Silva Jr. e Palácios, propõe uma classificação do desenvolvimento do jornalismo na web (Tabela 1).

Tabela 1 - As gerações do webjornalismo

\begin{tabular}{lll}
\hline \multicolumn{2}{c}{ Webjornalismo } \\
\hline $\begin{array}{l}\text { Primeira geração } \\
\text { (Fase de transposição) }\end{array}$ & $\begin{array}{l}\text { Segunda geração } \\
\text { (Fase da metáfora) }\end{array}$ & $\begin{array}{l}\text { Terceira geração } \\
\text { (Fase da exploração das } \\
\text { características do suporte web) }\end{array}$ \\
\hline $\begin{array}{l}\text { O conteúdo de jornais } \\
\text { impressos existentes são } \\
\text { copiados para a web. }\end{array}$ & $\begin{array}{l}\text { O conteúdo de jornais impressos } \\
\text { existentes são explorados / }\end{array}$ & $\begin{array}{l}\text { O conteúdo, não só de jornais } \\
\text { impressos, são explorados com maior } \\
\text { profundidade na web. }\end{array}$ \\
\hline
\end{tabular}

Fonte: Elaborado pela autora a partir de MIELNICZUK, 2003, p. 48-50.

1 Entende-se por elite "uma minoria que detém o poder baseado em condições sine qua non em uma dada sociedade. Estas condições devem ser reconhecidas socialmente e vão determinar os tipos de elites vigentes em cada época (elite religiosa, militar, intelectual, cultural, financeira, política...)" (BORN, 2008b). 
Com base em Mielniczuk (2003), percebese que na primeira geração do jornalismo na web não há preocupação em explorar o conteúdo existente na forma impressa no novo suporte, há apenas uma cópia, ou seja, uma transposição das informações jornalísticas impressas para a internet. Já na segunda geração, surge a iniciativa em trabalhar com esse novo suporte, por meio de linkes², e-mail, últimas notícias, por exemplo. Esta fase é também chamada de "metáfora", POR se basear no jornal impresso para elaboração das interfaces dos produtos para a web. $\mathrm{Na}$ terceira e última geração, desvincula-se do caráter essencialmente de jornais impressos e explora-se com maior profundidade as possibilidades oferecidas pela web, com recursos multimídias como sons e animações, e de interatividade, como chats, fóruns de discussão, atualização permanente no webjornal, não se limitando às "últimas notícias" da segunda geração.

Schwingel (2005, p. 10) complementa as três gerações do jornalismo na web incluindo a quarta, composta pela "utilização de bancos de dados complexos (relacionais, voltados a objetos) através da utilização de ferramentas automatizadas e diferenciadas (sistemas para a apuração, a edição e a veiculação das informações) na produção de produtos jornalísticos", ou seja, um jornalismo participativo. Nota-se que essas gerações específicas do jornalismo representam aideia do "ajeitamento" apontado anteriormente.

O jornalismo na internet é fortemente retratado nos portais, como UOL e Terra. Portal, sinônimo de sítio, é considerado por Barbosa (2003) como meio de massa na internet. Para tanto, a autora cria uma categoria específica para o jornalismo digital, denominando-o como “jornalismo de portal”.

O jornalismo de portal normalmente contempla uma oferta contendo hipertextos, áudio, vídeos, serviços, entretenimento e compras. Ferrari (2003) explora os elementos comuns aos portais exemplificando: ferramenta de busca, comunidades, comércio eletrônico, e-mail gratuito, entretenimento e esportes, notícias, previsão do tempo, chat, discos virtuais, homepages pessoais, jogos online $e^{3}$, páginas amarelas, mapas, cotações financeiras, canais, mapa do site e personalização.

Os provedores de internet, constituídos em 1996, passam a adotar o modelo de portal, sendo que este modelo ganhou força no Brasil "sobretudo pelo potencial para convergir grandes audiências e, com isso, visibilidade para seu conteúdo e serviços, atraindo publicidade e gerando possibilidades para o comércio eletrônico" (BARBOSA, 2003, p. 166).

Nesse contexto, pode-se destacar algumas características da web, como: interatividade ${ }^{4}$, caráter dinâmico, disponibilidade e acesso instantâneo (sob demanda) (FRAGOSO, 2006). Ferrari (2003) compartilha com Fragoso (2006) sobre as características da internet, na medida em que destaca a interatividade, o dinamismo e ainda acrescenta a personalização. Além disso, o "público online é mais receptivo para estilos não convencionais", como, por exemplo, o uso de verbos fortes e humor (FERRARI, 2003, p. 49).

Apontando mais claramente as características comuns entre televisão e web, Fragoso (2008, p. 5) expõe que a “diferença é que naqueles meios é o emissor quem determina quando a informação é disponibilizada ('vai ao ar'), enquanto na web o material permanece sempre disponível, para ser acessado quando convenha”.

\section{Vida cotidiana contemporânea}

Estamos vivendo em "um mundo de imagens, de celebridades, de culto à aparência e de busca da visibilidade" (SILVA, 2006, p. 8). "A ordem é viver o aqui e agora, cuidar do corpo, da aparência, compartilhar as emoções, se entregar, se gastar, é o lúdico, é o prazer, é o estar-junto com os outros" (BORN, 2007, p. 21). Há a valorização da beleza, da juventude, da magreza e do medo do envelhecimento: "aparentar menos idade do que se tem é uma aspiração contemporânea legítima" (LIPOVETSKY, 2007, p. 66).

2 Link é o mesmo que hyperlink. "Elemento básico de hipertexto, um byperlink oferece um método de passar de um ponto do documento para outro ponto no mesmo documento ou em outro documento" (FERRARI, 2003, p. 99)

3 Online "quer dizer 'estar em linha', ou estar ligado à rede ou a um outro computador" (FERRARI, 2003, p. 101)

4 De acordo com Fragoso (2006, p. 4), interatividade é “um tipo especial de interação com produtos midiáticos diversos que se traduz em possibilidades de ação sobre o desenvolvimento das mensagens mais diretas do que aquelas usualmente viabilizadas pelas mídias "tradicionais"'. 
As festas, os lazeres, as férias, a moda, o supérfluo, as incitações ao prazer invadem o espaço da vida cotidiana tornando-se desejos e aspirações legítimos em todos os grupos sociais (LIPOVETSKY, 2007): "[...] a festa aparece como teatro simbólico das viscissitudes identitárias do grupo, portanto, como lugar de ritualização dos conflitos em torno do controle social" (SODRÉ; PAIVA, 2002, p. 107, grifo nosso)

Silva (apud LIPOVETSKY, 2007, p. 18) afirma que "é preciso estar sempre conectado. Privado e público se confundem. Cada vez mais, cada um quer ser protagonista e contar a sua vida num blog ou noutro mecanismo de exposição o que antes era reservado à família, aos vizinhos, aos amigos", e a festa particular e sua veiculação pública é uma forma dessa divulgação.

Além dessas características da sociedade contemporânea apontadas, há ainda o enfraquecimento da religião. "Ainda que a fé em Deus nunca possa ser extinta, tudo indica que a religião deixou de desempenhar o papel confrontador que tivera no passado" (LIPOVETSKY, 2007, p. 7).

Silva (2006, p. 37) reforça a importância da religião quando afirma que "não existe cultura sem religião, sem rituais, sem crença". E o autor vai além: "no cotidiano, sabemos que as religiões existem e expressam um patrimônio da humanidade" (SILVA, 2006, p. 39). Uma sociedade sem religião é como se fosse uma cultura sem imaginário.

Além do aspecto religioso, há ainda elementos como amor, beleza, prestígio, êxito, poder, que são bens não comercializáveis e, portanto, objetos de desejo (LIPOVETSKY, 2007). Silva (2006, p. 147) compartilha dessa visão quando expõe que "amor e reconhecimento (glória, admiração dos outros, recompensa pelo mérito) são dois motores da vida".

Todos esses elementos são normalmente explorados pela divulgação comercial. Lipovetsky (2007) coloca que a publicidade ${ }^{5}$ bombardeia os consumidores, cria necessidades supérfluas, revelaimagem de felicidade, promessa de beleza e saúde, sonhos, desejos, modelo ideal de vida. Silva (2006, p. 135) também defende que "a publicidade estimula a pensar que a felicidade se mede em números, em despesas, em gastos, em aquisições, em consumo, como se a vida fosse um livro dos recordes ou um balancete".
O estilo de vestir é uma das maiores armas de distinção social, pois identifica os membros de uma tribo e exclui os demais da nossa sociedade. Separa os que têm bom gosto dos que têm mau gosto (SILVA, 2006). Sodré e Paiva (2002, p. 17, grifo nosso) lembram que "gosto, em Kant, é conceito de sentido muito amplo, que designa a disposição para uma atitude estética". Pensando mais restritamente, os autores afirmam que se emite um juízo de valor que gira em torno da beleza de um objeto, exemplificando com uma obra de arte. O belo se refere ao bom e o feio se refere ao mau. Essa noção de gosto opera com doses de subjetividade: "[...] ter bom gosto é ser capaz de corresponder ao gosto determinado por quem fez o gosto numa certa época" (SILVA, 2006, p. 112).

Nessa linha de pensamento emerge a noção de brega explorada por José (2002). Dentre suas hipóteses de conceituação de brega, destaca-se sob a ótica do gosto: "[...] uma qualificação de mau gosto que tem referência opositiva um outro padrão estético, determinado pela elite cultural, denominado chique" (JOSÉ, 2002, p. 37). De uma forma geral, a autora aponta o brega como sendo um produto massificado ${ }^{6}$ de consumo, baseado no padrão estético da elite.

José (2002, p. 33) ainda reforça que "[...] a classe dominante homogeneíza os processos sígnicos como clichês, slogans e signos cristalizados, isto é, processos em que as significações sejam únicas, aquelas que assegurem as normas sociais". E completa afirmando que estes elementos produzem significações, que são adotadas como formas definitivas e sem relativizações.

Baseada no semioticista Charles Peirce (1974 apud JOSÉ, 2002, p. 39) expressa que,

como os objetos falam sobre seus usuários, cada segmento social deve ter um conjunto de objetos selecionado a partir da identidade que se estabelece entre o usuário e o seu respectivo objeto; o objeto contém uma significação que funciona como uma tradução de valores que distinguem um de outro segmento social, isto é, como um interpretante.

\footnotetext{
5 Acredita-se que os autores Lipovetsky e Silva possuem uma visão europeia da noção de publicidade, entendendo como toda e qualquer divulgação de caráter comercial, paga ou não.

6 Segundo Blumer (1971 apud JOSÉ, 2002, p. 25), "massa é um grupo coletivo elementar e espontâneo, representada por pessoas que participam de um comportamento de massa, que procuram agir pela convergência de escolhas individuais".
} 
Esses objetos podem ser tanto do âmbito do brega quanto do kitsch, pois os dois termos caminham lado ao lado.

Segundo Moles (2007, p. 11) o kitsch"constitui um estado de espírito que, eventualmente, se cristaliza nos objetos". É um fenômeno social, oriundo do mundo burguês, com uma carga pejorativa, tem como fio condutor o adorno, a decoração da vida cotidiana.

Para melhor compreensão, a Tabela 2 evidencia a linha tênue entre o brega e o kitsch, suas semelhanças e dessemelhanças, com base em José (2002) e Moles (2007).

A partir da Tabela 2, entende-se e exemplifica-se que, no brega, pega-se algo de menos valor e "pinta-se de dourado" para parecer que é ouro, isto é, pega-se algo de menor qualidade e faz-se passar por algo de maior valor. E muitas vezes o brega é caro, é ostentação. Mas independente de ser caro ou barato, é de mau gosto porque avisa: "ei, eu sou rico, eu sou da elite" (em geral econômico-financeira).

Por outro lado, o kitsch é a diluição de algo de maior valor, que é popularizado em versão reproduzível, como, por exemplo, as cópias da Torre Eiffel - a torre não é kitsch, é arte, mas as torrezinhas de plástico escrito "Paris" que as pessoas compram como souvenir são kitsch.

José (2002, p. 78) ainda arrisca uma afirmação: “[...] os segmentos médios da sociedade, em época de ascensão do poder aquisitivo, têm para si a produção do objeto kitsch e, em épocas de recessão, têm para si a produção do objeto brega". Enquanto que Moles (2007, p. 224) alfineta "[...] não existe ser humano, artista, asceta ou herói, que não tenha algo de kitsch na medida em que seja cotidiano".

Tabela 2 - Semelhanças e dissemelhanças entre brega e kitsch

\begin{tabular}{|c|c|c|}
\hline & Brega & Kitsch \\
\hline Academia científica & $\begin{array}{l}\text { Sem espaço. Discutido apenas por } \\
\text { Carmen José, que propõe uma } \\
\text { conceituação }\end{array}$ & $\begin{array}{l}\text { Já discutido por autores como Abraham } \\
\text { Moles e Umberto Eco }\end{array}$ \\
\hline Época do surgimento & \multicolumn{2}{|c|}{ Capitalismo } \\
\hline \multirow{2}{*}{ Origem } & \multicolumn{2}{|c|}{ Padrão estético da elite } \\
\hline & \multicolumn{2}{|c|}{ Elemento mediador da relação dos homens no cotidiano } \\
\hline \multirow{2}{*}{ Mercadoria } & \multicolumn{2}{|c|}{ Produtos culturais industrializados para consumo de massa } \\
\hline & Mais barata, porém com menos qualidade & Mais barata \\
\hline Base da mercadoria & Artesanato e manufatura & Arte \\
\hline \multirow{3}{*}{ Público-alvo } & $\begin{array}{l}\text { Não tem informação sobre o valor de uso } \\
\text { (fonte de informação baseada na cultura } \\
\text { popular) }\end{array}$ & $\begin{array}{l}\text { Tem informação sobre o valor de uso } \\
\text { (fonte de informação baseada na cultura } \\
\text { superior) }\end{array}$ \\
\hline & $\begin{array}{l}\text { Busca sentir-se como a elite (tem a ilusão } \\
\text { de prestígio social) }\end{array}$ & $\begin{array}{l}\text { Busca harmonia (tem a ilusão de uma } \\
\text { experiência estética) }\end{array}$ \\
\hline & Classe baixa & Classe média \\
\hline Exemplos & $\begin{array}{l}\text { Produtos já descartados pela elite; } \\
\text { saldos ou pontas de estoque; uso de } \\
\text { produtos de forma inadequada }\end{array}$ & Souvenir, cópias, imitações \\
\hline
\end{tabular}

Fonte: A autora, a partir de JOSÉ, 2002; MOLES, 2007. 


\section{Estratégia metodológica}

O tipo de pesquisa adotado neste artigo é denominado como exploratória, que busca uma aproximação com o problema de pesquisa, permitindo aprimorar ideias (GIL, 2002). Nesse sentido, trata-se de uma pesquisa com vertente qualitativa. O método utilizado éo estudo de caso que "surge do desejo de se compreender fenômenos sociais complexos" (YIN, 2005, p. 20).

Para selecionar o corpus de análise, primeiramente realizou-se um mapeamento de todas as edições de Sociedade exibidas em 2009, até 16 de abril. ${ }^{7}$ Assim, percebeu-se que normalmente ${ }^{8}$ os programas seguem um padrão de veiculação: comercial publicitário, abertura, comentário sobre os assuntos que serão vistos (festas de casamentos, formaturas, aniversários, etc.) destacando (imagens e nomes) de quem ele entrevistou e o local do evento. Depois há registro dos próximos eventos, convites de inaugurações e lançamentos, e posteriormente são mostrados os destaques da parte inicial do programa, com alguns comerciais publicitários intercalados. Por fim, faz-se a divulgação do programa na internet e pelo número de celular. $\mathrm{O}$ fechamento é igual à abertura.

Em virtude desse padrão encontrado, selecionaram-se quatro edições do Sociedade em 2009, de um total de 19 (de 30 de outubro de 2008 a 16 de abril de 2009) disponíveis na internet, conforme demonstra a Tabela 3. Essas quatro edições foram escolhidas pelo fato de abordarem assuntos diferentes: expectativas para 2009, festa temática particular, aniversário, conversa com estilista, festa de um clube social, lançamento da coleção de um estilista e aniversário de 15 anos.

Tabela 3 - Corpus da pesquisa

\begin{tabular}{|c|c|}
\hline \multicolumn{2}{|r|}{ Programa Sociedade } \\
\hline Meios de comunicação veiculados & $\begin{array}{l}\text { Televisão } \\
\text { Internet }\end{array}$ \\
\hline Veículos de comunicação & $\begin{array}{l}\text { Canal } 20 \text { (Porto Alegre), pela Net Serviços } \\
\text { TVI, pelo portal gratuito http://www.tvi.com.br/v2/portal/ }\end{array}$ \\
\hline Início da veiculação & $\begin{array}{l}\text { Na televisão, em } 2000 \\
\text { Na web, em } 28 \text { de março } 2008\end{array}$ \\
\hline Apresentador & Odalgir Lazzari \\
\hline Periodicidade / frequência & $\begin{array}{l}\text { Semanal (programa inédito nas quintas às } 19 \text { horas, na } \\
\text { televisão; e reprises nos domingos, às } 16 \text { horas, segundas, às } 9 \\
\text { horas, terças, às } 15 \mathrm{~h} 30 \text {, sextas às } 18 \mathrm{~h} 30 \text {, e sábado, às } 14 \mathrm{~h} 30 \text { ); e } \\
24 \text { horas pelo portal }\end{array}$ \\
\hline Duração & Aproximadamente 30 minutos \\
\hline Corpus de análise & Edições de 5 e 15 de janeiro, 12 de março e 16 de abril de 2009 \\
\hline
\end{tabular}

Fonte: Elaborado pela autora.

Pode-se ter uma ideia do potencial de pessoas que assistem ou já assistiram ao programa Sociedade pela televisão com base no número de aproximadamente 152 mil assinantes da Net Cidade Porto Alegre e de quase 485 mil pessoas expostas. ${ }^{9}$
Para a análise do corpus, empregou-se a técnica de análise de conteúdo de Bardin (2007) de forma mais ampliada; isto é, além da análise do texto (dimensão verbal), houve também, em menor grau, a análise da imagem (dimensão não verbal), baseada na análise de imagens em movimento proposta por Rose (2002).

\footnotetext{
7 Data do início da elaboração deste artigo.

8 Com exceção do primeiro programa do ano de 2009, o qual Odalgir Lazzari chamou de "especial".

9 Até a conclusão deste artigo, a Net Serviços não havia disponibilizado a audiência do programa Sociedade, e o portal TVI ainda não havia fornecido o número de Page views.
} 


\section{Apresentação e análise dos resultados}

Conforme visto anteriormente, o programa Sociedade com Odalgir Lazzari iniciou sua veiculação na televisão em 2000, e em 2008 passou a ser veiculado também na internet, revelando a previsão de Gilder (1996, p. 31) de que "a era da televisão está cedendo o passo às tecnologias interativas bem mais ricas da era do computador". De acordo com as gerações do jornalismo na web, verifica-se que o programa Sociedade está na primeira fase, a chamada transposição (MIELNICZUK, 2003), uma vez que se trata simplesmente da reprodução televisiva na web, ou seja, no mesmo formato e com a mesma linguagem.

Percebe-se também que o perfil do públicoalvo mantém-se o mesmo, uma vez que tanto os consumidores de TV por assinatura quanto os internautas são pertencentes às classes sociais mais elevadas. Vilches (2003, p. 39) revela essa migração digital evidenciando que "o abismo entre conectados e não conectados não é regional, mas de classes. [...] a elite, emigra para não ficar excluída do mais potente âmbito de desenvolvimento comunicativo que jamais existiu". E completa: "A emigração para a rede converter-se-á no signo de progresso pessoal" (VILCHES, 2003, p. 40). A ideia é a mesma da migração do campo para a cidade.

$\mathrm{Na}$ internet, o Programa é veiculado no portal público TVI, seguindo a proposição de Barbosa (2003). Esse portal se intitula o "maior portal da América Latina em termos de vídeos de todos os gêneros" e apresenta, além dos Programas de TV online, cinema, música, esportes e notícias, sendo esta última uma característicajáapontada por Ferrari (2003).

Os eventos registrados pelo Sociedade são essencialmente festas, celebrações, ou seja, teatro simbólico das vicissitudes identitárias do grupo, conforme apontam Sodré e Paiva (2002). Silva (2006) ainda destaca a mistura entre caráter privado e público, mostrando que a cada dia que passa as pessoas querem ser protagonistas e expor suas vidas além das barreiras da família, dos amigos e dos vizinhos.

Encontraram-se nove categorias temáticas, classificadas como: mar de afetividade, império da adjetivação, o popular e o elitizado, pluralidade de elites $^{10}$, era da aparência, reino de Deus, bordões, ajudando a pagar a conta e retroalimentação.

A categoria temática "mar de afetividade" foi a mais expressiva. Ela revela o afeto com que o apresentador trata seus participantes e vice-versa, e também como os participantes se tratam entre si, conforme trechos de algumas falas: "Um beijo carinhoso"; "Tu merece tudo isso e muito mais"; "Minha querida amiga Cristina Piccoll"; e "Muito obrigado, é um prazer estar contigo sempre". ${ }^{11}$

Lipovetsky (2007), assim como Silva (2006), já evidenciou a importância do amor nos dias atuais e no programa Sociedade isso aparece claramente. O prestígio é outro importante bem não comercializável que as pessoas desejam. Dessa forma, nessa categoria emergem também elogios ao programa, como revela a fala do vice-prefeito da capital gaúcha, José Fortunati: "[...] neste teu belíssimo programa, que tem se mantido ao longo do tempo com tanta qualidade, levando tanta informação, especialmente sobre a nossa cidade".

Nesse sentido, percebe-se no programa Sociedade o vigor do reconhecimento (glória, admiração dos outros, recompensa pelo mérito) apontado por Silva (2006) como um dos motores da vida contemporânea.

Além disso, essa categoria ainda destaca as expressões proferidas pelos participantes e pelo próprio apresentador, que sugerem um relacionamento de outrora, uma vez que demonstram a frequência dos encontros, conforme nota-se em algumas falas destacadas: "Odalgir, é uma grande alegria, enorme satisfação em voltar a conversar contigo" e "E um privilégio ter você aqui conosco mais do que nunca. Você sabe, tens nos acompanhado".

A segunda categoria temática que mais se destaca é denominada como "império da adjetivação", pois o apresentador emprega predominantemente muitos adjetivos em todas as edições do programa Sociedade para se referir tanto aos homens e mulheres com os quais conversa e quanto aos locais de onde registra os eventos: "Ela é linda, amável, atenciosa, inteligente e muito glamourosa" e "Ele é um dos homens mais elegantes de Porto Alegre, uma figura muito querida, um ser humano extraordinário, grande profissional, mas assim com uma babilidade, com um talento, com um brilhantismo".

\footnotetext{
${ }^{10}$ Noção já adotada por Born (2008c).

${ }^{11}$ Todas as falas citadas dos participantes e do apresentador do programa Sociedade foram retiradas do site $<$ www.tvnainternet.com $>$. Ver LAZZARI, 2009.
} 
Percebe-se que alguns participantes também recorrem aos adjetivos, como, por exemplo, Bibo "Numa festa moderna, linda, fashion e arrojada [...]", e Sebastião: “[...] o Garcia é uma grande figura [...] é uma figura maravilhosa, não é? Ele e a Rosa formam um casal espetacular, né?Uma família de bem".

Nesse sentido, os elementos de beleza e poder também estão presentes no Sociedade, conforme já destacado por Lipovetsky (2007).

Além disso, nota-se que essa categoria expressa o "bom gosto". Todas as edições do programa evidenciam os objetos consumidos por pessoas de bom gosto, conforme Sodré e Paiva (2002), emite-se um juízo de valor que gira em torno da beleza de um objeto, como se o belo se referisse ao bom e o feio ao mau. Essa categoria é revelada em expressões do apresentador, como por exemplo: "Que bom. Muito bonito. Muito interessante, de muito bom gosto"; "Tá muito elegante, muito elegante nesse vestido da Milka, de muito bom gosto" e "Sempre elegante, de muito bom gosto, figura de nossa sociedade".

Destaca-se a fala de um dos participantes, Rui Sphor, que demonstra cautela no uso da expressão "bom gosto": "Olha, é uma experiência nova que en acredito que é muito normal para quem trabalha com beleza, quem trabalha com o denominado 'bom gosto', que eu ponho entre aspas para saber o que é realmente bom gosto".

Já a categoria temática intitulada "o popular e o elitizado" surge na medida em que há mistura de elementos populares com elementos elitizados, tanto no texto verbal (escrito e falado) quanto no texto não verbal (imagens).

O popular aparece nas seguintes passagens do programa: "Vocês estão de parabéns, estão abrindo com chave de ouro"; "[...] estão começando com o pé direito [...]" e "A sociedade toda grita pela festa".

Já o elitizado surge nos seguintes trechos: "[...] mais uma vezo o clã Sirena [...]"; "Um pai, quando tem a sua filha fazendo 15 anos, eu acredito que deve ter belas recordações de quando ela era bambina"; "[...] para abraçar esse querido amiga que estava de cumple años [...]" e "V im para estarjunto de vocês, junto de toda essa pleia de amigos [...]".

Percebe-se que o apresentador busca utilizar uma linguagem rebuscada na medida em que emprega termos como "pleia", "clã", e também palavras em língua espanhola, "cumple años", e italiana, "bambina". Por outro lado, emprega ditados populares como "chave de ouro" e "começar com o pé direito", como também a figura de linguagem hipérbole "grita pela festa", conforme visto anteriormente.
Além disso, percebe-se a presença de elementos símbolos da elite. José (2002) afirma que esses elementos produzem significações e são adotados de forma definitiva como sendo o padrão estético a ser seguido, pois "a classe dominante homogeneíza os processos sígnicos como clichês, slogans e signos cristalizados" (JOSÉ, 2002, p. 33). Na abertura do programa há imagens do apresentador pegando um anel dourado dentro de uma caixa preta, depois pegando duas abotoaduras amarelas dentro de outra caixa, uma gravata borboleta, um vidro de perfume, depois uma taça de espumante e, por fim, aparece usando smoking.

Nesse contexto, nota-se que o popular e o elitizado caminham juntos no decorrer do programa.

Outra categoria temática evidenciada no Sociedade é a "pluralidade de elites", pois embora o programa seja direcionado às classes sociais altas, classificadas de acordo com sua remuneração, percebe-se que há vários tipos de elites que não se restringem à condição econômica.

Entre os tipos de elite presentes nas edições dos programas analisados destaca-se a elite profissional (empresários, advogados, arquitetos, produtora de eventos, etc.), conforme as falas do apresentador: "Ele é um empresário de destaque da nossa capital"; "Ele é o big boss da Kia Sun Motors [...]"; "Este jovem empresário de nossa capital [...]"; "[...] advogada de classe, a nossa querida Barbara Sucasas Pozzebon" e ainda "[...] arquiteto". Esse tipo de elite ainda pode ser subclassificado como elite profissional relacionada às artes (estilista, artista plástico, consultora de moda). Há também a elite política (vereador, vice-prefeito, etc.); a elite estética, em virtude dos títulos de beleza apresentados por Odalgir; a elite midiática, dos clubes sociais, e a elite econômicofinanceira, mas esta é somente expressa na comunicação não verbal.

A quinta categoria temática diz respeitoà “era da aparência", pois se nota que o apresentador e os participantes do programa estão "produzidos", ou seja, demonstram cuidado com o vestuário. Nessemomento, é importante relembrar que estilo de vestir é uma das maiores armas de distinção social (SILVA, 2006).

$\mathrm{O}$ apresentador Odalgir nunca aparece de smoking (como sugere a imagem da abertura do programa), mas usa calça e camisa com modelos/ cores que não seguem o padrão estético imposto pela elite, podendo até ser rotulado como brega, uma vez que José (2002, p. 44) afirma que "brega é 
um modo de selecionar e associar objetos e signos disponíveis para o consumo; é um conteúdo único (querer ser igual à elite)".

Essa categoria foi embasada essencialmente nas imagens das pessoas. Em sua maioria, mulheres maquiadas, com cabelos soltos e muitas joias, oram usam vestidos, ora usam calças e blusas mais elaboradas. Em minoria, os homens, ora de ternos, ora de camisa e blazer, mas todos usando relógios. Nesta categoria emerge a noção de brega, com base em José (2002), pois há algumas pessoas que utilizam vestimenta já descartada pela elite (por exemplo: camisa e suspensório), evidenciando que não têm informação sobre o valor de uso, mas estão sendo registradas por outra condição social, que não a econômico-financeira. "Nunca tivemos tanto acesso ao ter; nunca aspiramos tanto ao ser" (BORN, 2007).

A sexta categoria é denominada como "reino de Deus", porque o apresentador sempre se refere à fé: "Deus já iluminou vocês e vão faz̧er um trabalho maravilhoso com certeza"; "Muito sucesso em 2009, que Deus te abençoe e ilumine"; "[...] e desejo novamente que Deus abencoe e ilumine [...]" e "Que bom, que Deus ilumine [...]". $\mathrm{E}$ as vezes até os participantes do Sociedade fazem essa alusão a Deus.

Embora Lipovetsky (2007) acredite que a fé em Deus não possa ser extinta, ele aponta o enfraquecimento da religião. Porém, no programa Sociedade, este enfraquecimento aparentemente não aparece, uma vez que tanto o apresentador quanto os participantes verbalizam sua fé.

Os "bordões" são a sétima categoria temática encontrada. É válido destacar que bordões são entendidos como expressões que o apresentador utiliza em determinadas partes de todas as edições do seu programa, como por exemplo: "Olá, tudo bem? Mais um programa Sociedade feito para você que está sempre conosco, aqui no Canal 20, o canal de Porto Alegre. Você vai ver no programa de hoje [...]”'.

Já a penúltima categoria temática, "ajudando a pagar a conta”, refere-se às divulgações que são apresentadas nos intervalos ou até mesmo pelo próprio apresentador no decorrer do programa e reforçadas por alguns participantes. Silva (2006, p. 176) comenta que "[...] temos a publicidade e seu poder de promover normas de consumo, de influenciar um número crescente de comportamentos individuais e coletivos".

Os intervalos comerciais (de 10 ou 30 segundos) são ocupados com maior predominância pelo supermercado Zaffari Bourbon, pela loja de móveis Gobbi Novelle, pela concessionária de automóveis Kia Motors e a rede Plaza Hotéis. Há ainda a divulgação da línica do Dr. Minuzzi, seguindo a afirmação de Lipovetsky (2007) sobre a promessa de beleza e saúde gerada pela publicidade. Durante o programa, destacam-se ainda as seguintes falas do apresentador: "Quer ir a Paris na semana Santa? Olha, tem uma oportunidade maravilhosa, a Tia Iara Viagens e Turismo [...]" e "Guarde então a grife Le Pret e você será uma mulher elegante chique e luxuosa". Dessa forma, evidencia-se a tentativa de modelo ideal de vida (LIPOVETSKY, 2007) e a demonstração da felicidade em gastos, em aquisições, em consumo (SILVA, 2006).

Por fim, a última categoria temática encontrada é a denominada "retroalimentação", que trabalha o processo de união dos veículos de comunicação que compartilham do mesmo caráter (mídia de colunismo social), isto é, os veículos se autorreferenciam. Esta categoria é expressa nas falas do apresentador: "[...] que está registrando tudo para a revista Caras"; "[...] estampa o último número da South Star Magazine [... ]" e "Tomorrow Magazine, em sua $29^{a}$ ediça traz na capa a empresária charmosa Andréa Druck".

Além das nove categorias temáticas expostas, pode-se afirmar que, de uma forma geral, percebe-se que o apresentador utiliza o recurso de repetição ao longo das edições de seus Programas, seja no uso dos adjetivos, seja no uso do tipo de elite que está sendo registrada.

\section{Considerações finais}

Este artigo buscou analisar o programa Sociedade com Odalgir Lazzari, veiculado tanto na televisão por assinatura quanto na internet. Nesse sentido, identificou-se as características dos tipos de mídias empregados pela atração: o programa atinge um público pertencente às classes sociais altas, tanto na televisão quanto na web, com um modo de distribuição da informação de "um-muitos", e ainda está na fase de transposição do jornalismo na web, não possuindo o caráter interativo, somente a característica de "sob demanda".

Além disso, verificou-se uma pluralidade de elites representada no Programa Sociedade desde a elite política, profissional, estética, até a elite midiática, de clubes sociais e econômica-financeira. 
BORN, A. M. H.

As categorias temáticas encontradas no Sociedade foram denominadas como "mar de afetividade", "império da adjetivação", "o popular e o elitizado", "pluralidade de elites", "era da aparência”, "reino de Deus", "bordões", "ajudando a pagar a conta" e "retroalimentação". Dentre elas, destacamse "mar de afetividade" e "império da adjetivação" como as categorias predominantes. $\mathrm{Na}$ análise individual de cada categoria temática, de uma forma geral, percebeu-se a aparição dos elementos mais valorizados na vida cotidiana contemporânea, como reconhecimento, amor, prestígio, poder e beleza. Em contrapartida, a categoria "reino de Deus" se mostrou como o elemento surpresa, uma vez que os autores defendem o enfraquecimento da religião nos dias atuais. E a questão do bom gosto e do brega também são contempladas.

\section{Referências}

ASSOCIAÇÃO BRASILEIRA DE TV POR ASSINATURA - ABTA. Indicadores do setor. jun. 2009. Disponível em: $<$ http://tvporassinatura.bizsolution.com. br/Panoramadosetor/IndicadoresdoSetor/tabid/109/ Default.aspx>. Acesso em: 27 jun. 2009.

BARBOSA, S. Jornalismo de portal: novo formato e categoria para o jornalismo digital. In: PALACIOS, M.; MACHADO, E. Modelos de jornalismo digital. Salvador: Edições GJOL; Calandra, 2003. p. 159-186.

BARDIN, L. Análise de conteúdo. Lisboa: Ed. 70, 2007.

BORN, A. M. H. A era do deleite. Zero Hora, Porto Alegre, RS, p. 21-21, 30 set. 2007.

. Mídia e vida social: uma reflexão sobre categoria, gênero e subgênero. Disciplina de Processos Midiáticos. jun. 2008a. 19 f. Nota de aula.

. As elites na mídia digital brasileira. Disciplina de Culturas e Tecnologias da Comunicação. Doutorado em Comunicação. dez. 2008b. 15 f. Nota de aula.

Os tipos de elites européias através da história. Disciplina de Culturas e Tecnologias da Comunicação. dez. 2008c. 28 f. Nota de aula.
COGO, D. Pesquisa em recepção na América Latina: perspectivas teórico-metodológicas. Portal da Comunicação INCOM-UAB, 23 fev. 2009. Disponível em: < http:// www.portalcomunicacion.com/por/pdf/aab_lec/48. pdf>. Acesso em: 19 abr. 2009.

ESCOSTEGUY, A. C. Estudos culturais: as margens de um programa de pesquisa. Revista da Associação Nacional dos Programas de Pós-Graduação em Comunicação, p. 2-16, ago. 2006. Disponível em: <http://www.compos.org.br/seer/index.php/ecompos/article/viewFile/77/77>. Acesso em: 19 abr. 2009 .

FERRARI, P. Jornalismo digital. São Paulo: Contexto, 2003.

FRAGOSO, S. Redes urbanas e redes digitais: considerações sobre governança eletrônica. In: PRYSTHON, Â.; CUNHA, P. (Org.). Ecos urbanos: as cidades e suas articulações midiáticas. Porto Alegre: Sulina, 2008.

FRAGOSO, S. Reflexões sobre a convergência midiática. Líbero, São Paulo, v. 8, n. 15/16, p. 17-21, 2006.

GIL, A. C. Como elaborar projetos de pesquisa. São Paulo: Atlas, 2002.

GILDER, G. A vida após a televisão: vencendo na revolução digital. Rio de Janeiro: Ediouro, 1996.

LAZZARI, O. Programa Sociedade. 2009. Disponível em: < http://www.tvnainternet.com/v2/video/0,VIDE O,1,2,1076,05012009,EX1,SOCIEDADE.html>. Acesso em: 3 maio 2009.

LIPOVETSKY, G. A sociedade da decepção. Barueri: Manole, 2007.

LUCA, L. de. Assista à televisão pela internet em seis portais brasileiros. 2009. Disponível em: <http://idgnow.uol.com.br/internet/2009/04/29/assista-televisaopela-internet-em-seis-portais-brasileiros $/>$. Acesso em: 10 maio 2009.

MIELNICZUK, L. Sistematizando alguns conhecimentos sobre jornalismo na web. In: MACHADO, E.; PALACIOS, M. (Org.). Modelos de jornalismo digital. Salvador: Calandra, 2003. p. 37-54.

MOLES, A. O kitsch: a arte da felicidade. São Paulo: Perspectiva, 2007. 
NET Mídia. 2009. Número de assinantes da Net por cidades. Disponível em: <http://nettv.globo.com/ NETServ/midia/canaislocais.htm $>$. Acesso em 3 jun. 2009.

ROSE, D. Análise de imagens em movimento. In: BAUER, M. W.; GASKELL, G. (Org.). Pesquisa qualitativa com texto, imagem e som: um manual prático. Petrópolis: Vozes, 2002. p. 343-364.

SCHWINGEL, C. Jornalismo de quarta geração. Niterói: Compós, 2005. Disponível em: <http://www. ufrgs.br/gtjornalismocompos/doc2005/carlaschwingel2005.doc.> Acesso em: 15 jun. 2009.

SILVA, J. M. da. Aprender a (vi)ver. Rio de Janeiro: Record, 2006.

SODRÉ, M.; PAIVA, R. O império do grotesco. Rio de Janeiro: Mauad, 2002.

TVI. Portal. Disponível em: < http://www.tvnainternet. com/v2/portal/>. Acesso em: 20 abr. 2009.

VILCHES, L. A migração digital. São Paulo: Loyola, 2003.

YIN, R. K. Estudo de caso: planejamento e métodos. Porto Alegre: Bookman, 2005.

Recebido: 18/02/2010

Received: 02/18/2010

Aprovado: 26/03/2010

Approved: 03/26/2010 